\title{
The impact of implemented management systems on the safety culture of work in production
}

doi:10.2478/mape-2019-0024

Date of submission to the Editor: 06/2018

Date of acceptance by the Editor: 07/2018

MAPE 2019, volume 2, issue 1, pp. 243-252

Krzysztof Nowacki ${ }^{*}$

ORCID ID: 0000-0003-2925-084

Silesian University of Technology, Poland

\section{SAFETY CULTURE OF WORK}

The beginnings of defining the concept of organizational culture date back to the XX century, when the company was begun to be seen as a social organization that was able to generate its own norms, values and, consequently, way of proceeding. Along with the development of science and knowledge about the methods of organization management, at the end of the twentieth century, the company was treated as an organization possessing its own, specific culture and analyzed by many researchers (Zohar, 1980), (Brown et al., 1986), (Dedobbeleer et al., 1991), (Cooper et al., 1994), (Clarke, 1999), (Mearns et al., 2001), (Johnson, 2007), (Guo et al., 2016), (Małysa et al., 2017), (Odom-Forren, 2019), (Thorgren and Caiman, 2019), (Stemn et al., 2019), (Schwartz et al., 2019), (Nite, 2019), (Gao et al., 2019), (Cooper et al., 2019), (Almklov et al., 2018), (Oberg, 2018), (Goncalves et al., 2018), (Stichler, 2018), (Naevestad, 2018), (Cox et al., 2010), (Glendon et al., 2010), (Małysa et al., 2016), (Markey et al., 2011), (Nielsen, 2014), (Sorensen, 2002), (Yangho et al., 2016) (Nowacki 2019).

Culture in organizational terms is a broad concept covering all aspects of its activity. By narrowing its area, the term culture of an organization may also refer to one narrow area of its activity. Such area is, for example, safety culture in particular work health and safety culture, understood as organizational and technical activities of all participants of the working process aimed at protecting employees from negative impacts of hazards occurring in the working environment resulting, in extreme cases, in an accident at work or development of occupational disease and, more frequent, factors causing nuisances during everyday tasks. Employee's protection is implemented with the use of specific technical means, safe organization of work and shaping of pro-safe human behaviour at work, taking into account the type and severity of potential hazards. Factors shaping the culture of the organization find a reference to the security of both the entire organization and its individual parts, including tangible values (e.g. devices, equipment) and intangible assets (e.g. management systems, technologies, employees' experience). (Hansen A., 1998) Safety culture can be seen as a set of rules, or unwritten rules of conduct. In case of a workplace, it refers to employees at all levels, constituting a subset of the general culture of an organization, and its shaping is a longterm, multidimensional and continuous stage, covering the whole structure of the enterprise (Ejdys J, 2010).

\footnotetext{
*krzysztof.nowacki@polsl.pl
} 
The goal of implementing of all management systems in an enterprise is to launch a repetitive, unified in all circumstances the assumed standard of conduct stated in the procedures. Such repetitive activities introduce in the organization a way of conduct that positively affects the functioning of the organization and its culture. This impact applies directly to the area to which a specific management system relates, but also indirectly affects the level of functioning of the areas that are not direct beneficiaries of the system but have some common elements. For example, the quality management system, through the mode and conditions of selecting subcontractors or suppliers, may affect the level of work safety through the implementation of the process itself or the use of materials/components with proven, repeatable and safe properties (Marans R. W., et al., 2018; van Nunen K., et al., 2018; Goldenstein-Cole K., 2017; Furman J., et al., 2018). The verification of the above dependences was adopted as the goal of the research presented in this article.

\section{METHODOLOGY OF RESEARCH}

Safety culture as a sum of employees' attitudes and beliefs is a phenomenon that can be measured, but the results obtained are only indirect results. Because the safety culture refers to the value system of all participants in the work process, in order to get to know the opinions of the stakeholders themselves, surveys addressed to employees at all levels were conducted. In order to assess the culture of work safety, an original questionnaire consisting of 63 questions was developed. The questions referred to the spheres of industrial enterprises activity and included seven areas:

- working environment,

- organization of work,

- knowledge in the field of safety,

- safety of machines,

- pro-safe activities,

- implementation and motivation to safe behaviour,

- communicating about safety.

Answers to the questions were provided on the five-point Likert scale, with the option of choosing "definitely yes", "rather yes", "yes", "rather not", "definitely not". In addition, the answer "not applicable" was possible. Based on the analysis of the results, points were awarded for each answer on a scale from 0 to 4 . The questionnaire was evaluated for reliability, obtaining for individual areas the $\square$ Cronbach index in the range of $0.74-0.85$ (required according to the Nunnally criterion minimum 0.7) (Nunnally J., 1976).

Assuming that the employees employed best know the company and, above all, they directly feel the impact of the safety climate prevailing in it, it was their opinion that they based on carrying the surveys. The questionnaire surveys of safety culture were conducted in 4 industrial plants located in Poland, receiving answers from at least $80 \%$ of employees. The order of the numbering of the plants results from the number of implemented management systems.

The plant's A business profile is the production of welded steel structures. Production takes place in old, over a hundred-year-old halls, adapted to current requirements and work standards. The plant has 5 certified management systems: ISO quality management system, ISO environmental management system, ISO/IEC information security management system, AQAP quality management system, $\mathrm{OHOHSAS}$ safety 
and health management system, internal Control System.

The business profile of plant $B$ is the production of a wide range of labels and tapes. The production takes place in a modern industrial hall built for the needs of the plant. The plant has 4 certified management systems: ISO quality management system, ISO environmental management system, OHSAS safety and health management system, ISO/TS quality management system.

The plant's $C$ business profile is the production of devices for measuring in liquid metals. The production takes place in modern halls built for the needs of the plant. The plant has 3 certified management systems: ISO quality management system, ISO environmental management system, PN-N occupational safety and health management system.

The business profile of plant $D$ is the production of welded steel structures. The production takes place in old, decades-old halls. The plant has 2 certified management systems: ISO quality management system, factory production control system.

\section{RESULTS OF THE RESEARCH}

The results of the research were compiled and submitted to statistical analysis. The obtained answers did not constitute a normal distribution, therefore, the median was used as the basis for the analysis (Aczer A, 2012). The maximum possible grade in total in the entire survey (in all areas of research) was 252 . The results obtained were shown in Fig. 1. It was stated that the best safety culture was assessed in plant B (median 183), and worst in plant $D$ (median 140). The evaluation of the safety culture of plants $A$ and $C$ was similar (median for $A-163$, for $C-152.5$ )

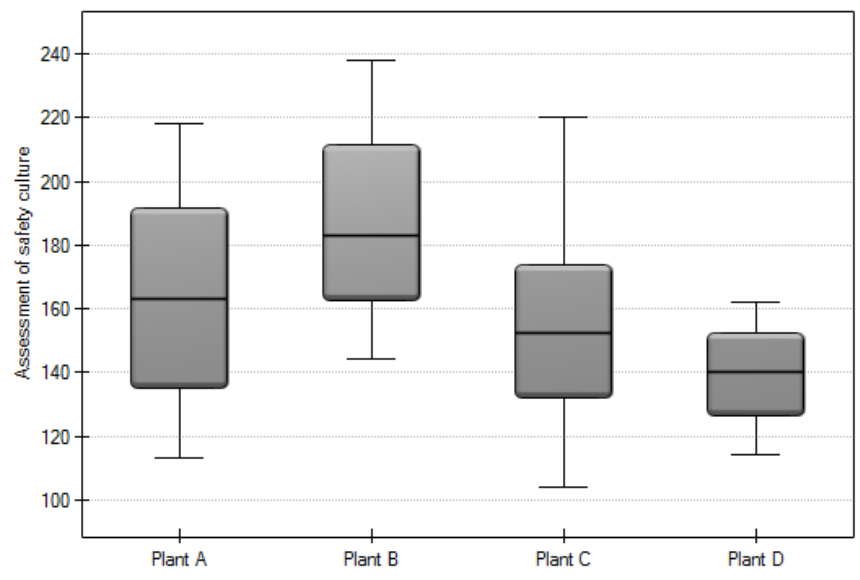

Fig. 1 Assessment of Safety Culture in the Examined Plants

While analysing the obtained research results, it was found that Plant $A$, despite the largest number of implemented certified management systems (5), obtained a lower assessment of work safety culture than Plant B with implemented 4 certified management systems. The reason for such an assessment may be the assortment of production and the adopted method of management of Plant B which aims at socalled "turquoise organization". The turquoise management is based on the paradigm of organizing teamwork which should give every employee sense of life, allow their development and offer space for creativity and innovation. Decisions in such an organization are made by people who know the subject and have predispositions, 
often after consulting others, and the rest of the team trusts them (Blikle A.J., 2017; Laloux F., 2016). This form of human resource management is an additional, informal management system, which in this case has a decisive impact on the assessment of the work safety culture by shaping a positive climate in the organization, including the safety climate that is felt throughout the organization. The results of safety culture in other plants confirmed the existing relationship between the number of implemented management systems and the culture of work safety (plant C - 3 systems, plant D - 2 systems). The relationship between the organizational level of the plant and the culture of work safety was noticed.

The obtained results were confirmed the density distribution of the safety culture assessment by employees, presented in Fig. 2. The total assessment of the employees of the plant $D$ (the lowest rated) was in the range of 114-162, while the individual summary assessments of the occupational safety culture of plant B were in the range of $144-238$.

The following is a detailed analysis of employees' answers to selected survey questions regarding:

- hazards related to moving and / or sharp elements,

- employee participation in defining work safety rules,

- in-house transport,

- personal protection equipment,

- evacuation trials,

- campaigns promoting safe behaviour at work.

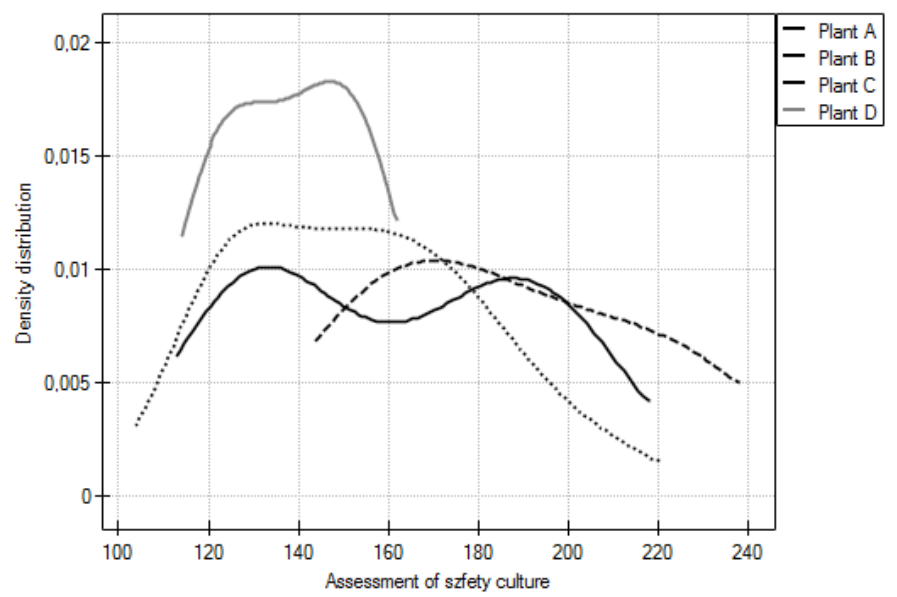

Fig. 2 Density Distribution Assessment of Work Safety Culture in the Examined Plants

All analysed plants run production activities and their employees have contact with both production materials and work tools. The assessment of threats related to moving and sharp elements was formulated as the question "are there any hazards in your workplace ...". This question was one of the reversed questions, because the answer YES was treated as a negative answer. In connection with the above, the answer was rewritten by saying "definitely yes", "rather yes" and "yes" as negative answers. The results are shown graphically in Fig. 3. It was found that in plant B only $20.6 \%$ of responses were negative, with $95.8 \%$ negative responses in plant $D$. The results of plant $A$ and $C$ were comparable. In addition, you can compare the response results of plants $A$ and $D$, which main production profile is welded constructions. 
Especially the answer "definitely yes" (9.7\% in plant A and $33.3 \%$ in plant D) indicates significant differences in the organizational level, which is the result of a culture of work safety.

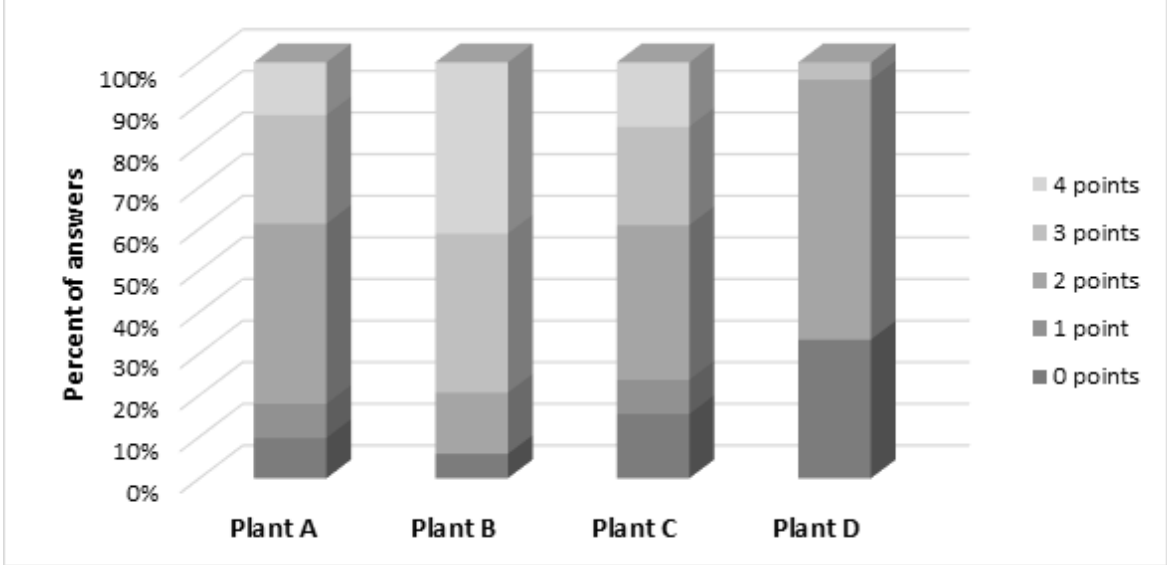

Fig. 3 Answers to the Question: "In My Workplace There Are (Not) Threats Related to Moving and/or Sharp Elements"

In accordance with the requirements of current standards for occupational safety management systems, an important element of such a system is employee's participation in creating a safe work environment. Such a cooperation, due to the very good knowledge of their own work position, is required, for example, in the area of consultations in defining the principles of work safety. Employees performing their duties on a daily basis are the best source of information and ideas regarding the possibilities and necessity to modify their work space. Accepting the answers: "definitely yes", "rather yes" and "yes" as positive answers, the results of the analysis of the answer to the question about employee involvement in defining security principles (Figure 4) indicate a large involvement of employees in this area. $93.2 \%$ of employees of plant $B, 79.1 \%$ of plant $A, 67.8 \%$ of plant $C$ and $58.3 \%$ of plant D declared that they could participate in such activities. It should be noted that in plants $A$ and $B$, that is in plants, which have the most certified management systems implemented, more than $3 / 4$ of employees are allowed to participate in defining security rules, while in the remaining more than half.

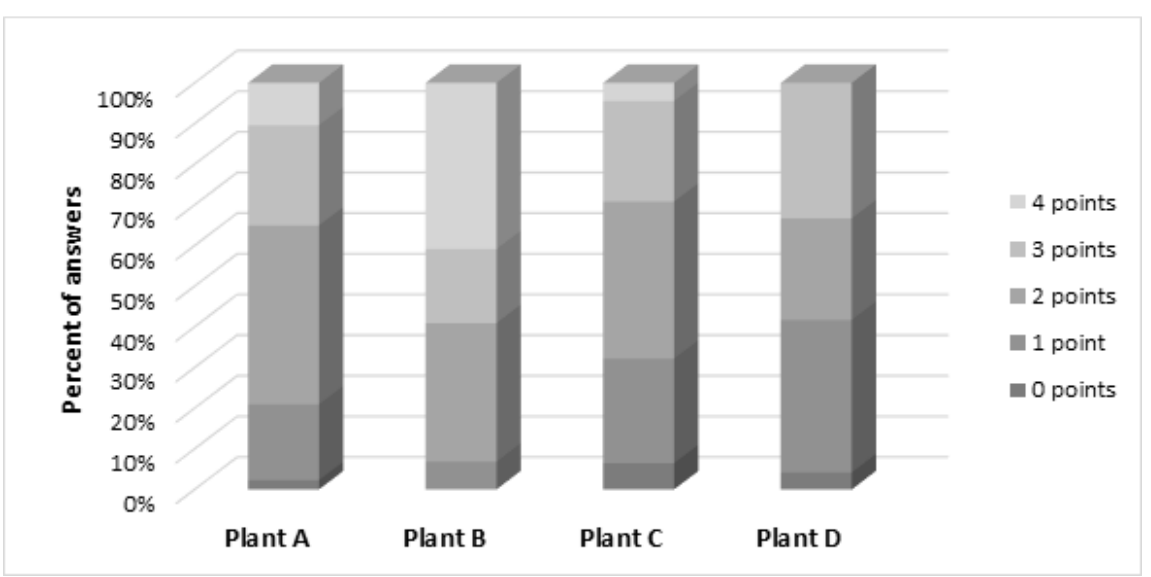

Fig. 4 Answers to the Question: "I Have the Opportunity to Participate in Defining the Rules Regarding the Safety of My Work" 
In-house transport is a frequent cause of accidents at work caused by moving machines or vehicles, resulting in the employee being knocked down or hit. The organization of in-house transport must cover the whole area of the plant, both inside and outside the production halls. The obtained results of the analysis in this area (Figure 5) allow to state that in-company transport in plants $\mathrm{A}, \mathrm{B}$ and $\mathrm{C}$, the plants with a larger number of implemented management systems than $D$ plant is well assessed by employees (100\% positive answers in plant B, $95.5 \%$ in plant $A, 92.3 \%$ in plant $\mathrm{C}$ ). In the case of plant $\mathrm{D}$, despite the fact that $72 \%$ of respondents positively assess the principles of internal transport, $28 \%$ of respondents, i.e. over a quarter of employees, claim that this transport is not well organized and may cause risks. Such results are a symptom of a low organizational culture in the area of work safety.

The selection of personal protective equipment is another carefully analysed activity in the field of work safety culture. A wide range of funds in the offer of manufacturers allows the selection of measures not only in terms of their protective properties but also their convenience and comfort during their operation. A non-ergonomic, and therefore uncomfortable, personal protective equipment may not be used by an employee, which will impact directly their safety and consequently, in the event of an accident at work or an occupational disease, on their health. The question regarding protection measures was another reversed question, which is why the results of the analysis were treated similarly as in the case of questions about threats with sharp and moving elements. The results of the study are shown graphically in Fig. 6 . It was stated that $93.1 \%$ of employees of plant $B$ are satisfied with the personal protective equipment at their disposal. The results of the evaluation for plants $A, C$ and $D$ are comparable, where 70.5 to $78 \%$ of positive responses were noted. The lowest score was recorded in plant $\mathrm{C}$, where almost $30 \%$ of employees say that individual protection measures interfere with their work. Such a situation may result not only from a relatively small number of implemented certified management systems (3) but above all from the nature of work, which in many cases requires precise manual work in gloves resistant to cuts or protecting against hot elements, which are often criticized by employees due to the relatively low comfort of their use.

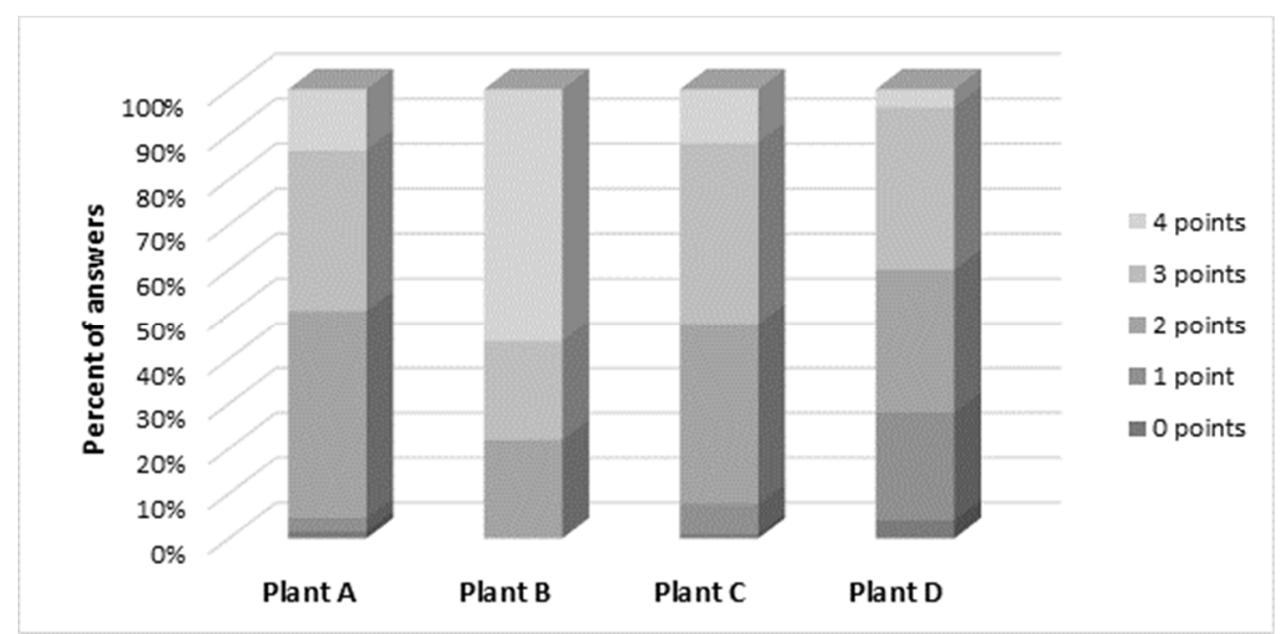

Fig. 5 Answers to the Question: "Intra-Company Transport is Well Organized and Does Not Cause an Additional Threat". 


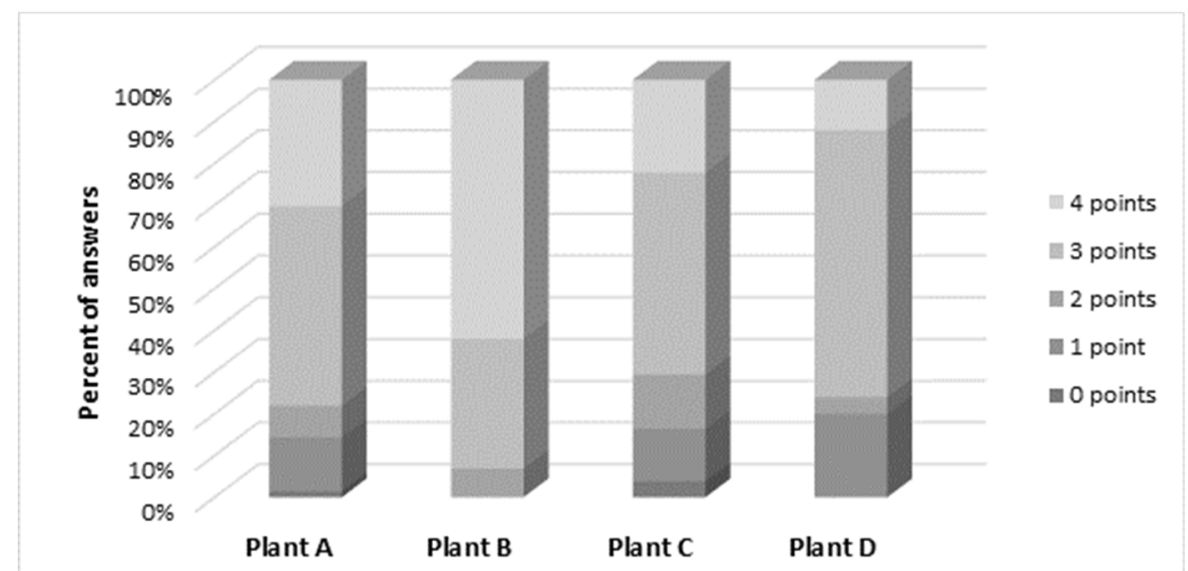

Fig. 6 Answers to the Question: "Personal Protection Measures (Don't) Interfere With My Work"

The employer's care for the health of employees results from the law, but above all it should result from the employer's moral responsibility for the safety of their employees. The effect of the above is for example organizing an effective way of evacuating them during dangerous, unforeseen events. Therefore, another indicator of the company's security culture is a repeatable, cyclical organization of trial evacuations. It is not enough to develop an evacuation plan with which employees will be familiarized once every few years during OHS training. In order to consolidate patterns of correct behaviour in such cases, which allows mainly to avoid panic among employees, is to develop the expected behaviour patterns that are only possible through trial evacuations. The analysis of the research results (Figure 7) allowed to state that in plants $A$ and $B$, it is in the plants where the largest number of management systems were implemented, practically all employees stated that the company is organizing trial evacuations. In plant C $23.1 \%$ of employees say that such evacuations do not take place. This result may be related to the employment structure in the plant, where some employees perform work on the basis of outsourcing contracts. Such employees, with seniority in the plant shorter than one year, may not have had the opportunity to participate in annual evacuation trials. At plant $\mathrm{D}$, all respondents stated that the company does not organize trial evacuations, which was also reflected in the overall assessment of the occupational safety culture (Figure 1).

Trial evacuations are in many cases obligatory. Non-compulsory, on the other hand, are additional activities of employers promoting pro-safe behaviour. Such activities can be any form of promotion from security corners, daily talks, to organized safety picnics, knowledge contests, etc. Its form depends only on the organizer's inventiveness bringing in the long-term increase of employee's awareness and commitment to safety issues, shaping a positive climate of safety and finally contributing to the growth of the work safety culture. The results of research on employees' involvement in pro-safe actions are presented in Fig. 8. It was found that more than $50 \%$ of employees of plant B (the most) take part in such activities. As a reminder, plant B is called "turquoise organization" otherwise known as "partner democracy", which rejects the principle of commission, bonuses, and issuing orders, based on the conditions of freedom, trust, partnership and cooperation (Blikle A. J., 2017; Laloux F., 2016). The lowest percentage involved in promotional activities $(16 \%)$ was recorded in plant $D$. 


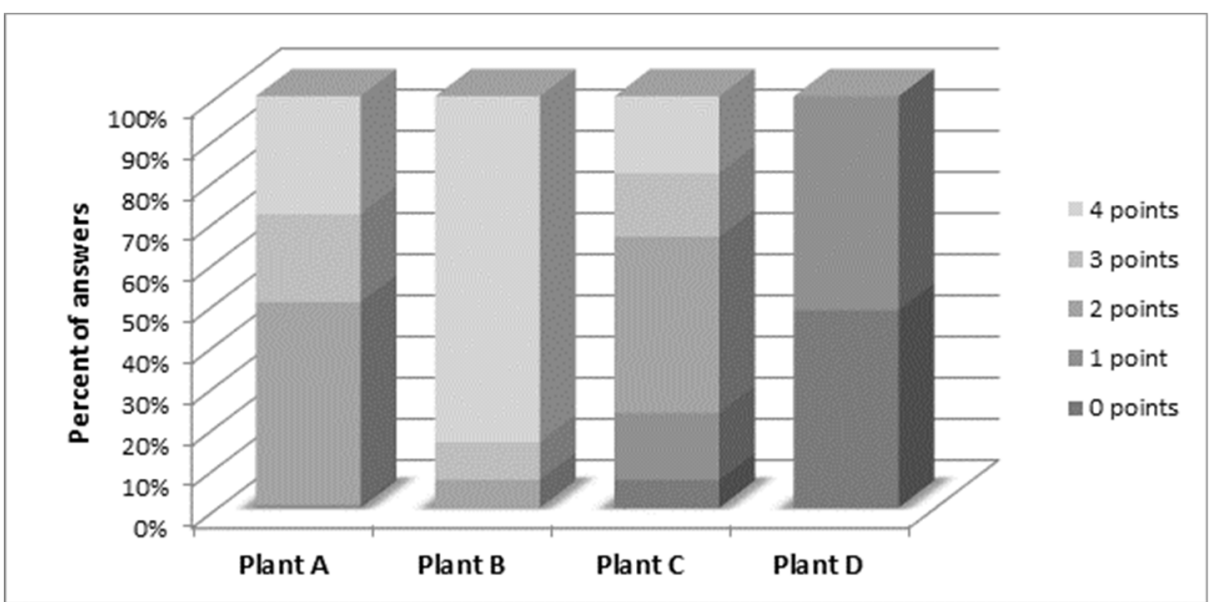

Fig. 7 Answers to the Question: "The Company in Which i Work Organizes Trial Evacuations in Which i Participate"

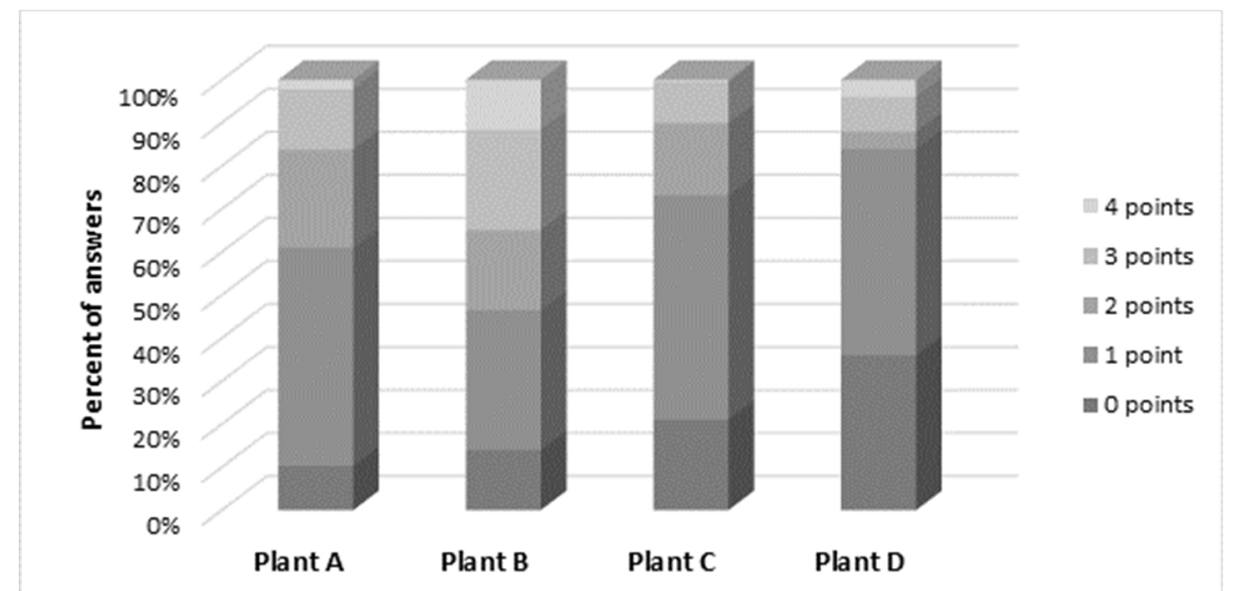

Fig. 8 Answers to the Question: "I Take Part in Actions Promoting Safe Behaviour During Work"

\section{SUMMARY}

All organizations, including industrial plants, are focused on competition and improving their competitiveness on the market. Their market position is built, for example through the implementation of management systems, the most common of which are: quality, environmental and work safety systems. In addition, many other specialised industry systems dedicated to specific processes, products or production control are being implemented. All of the human resources, material or information management systems implemented by the organization influence the level of organizational culture, including safety culture.

The obtained research results confirmed the thesis that the implemented certified management systems in industrial plants have a positive impact on the level of safety culture in these plants. It was found that the level of safety culture increases with the number of management systems operating in the plant. In addition, the influence of the organizational management form on the level of organizational culture was observed. In one of the surveyed enterprises, managed as so-called "turquoise organization", it was stated that despite the smaller number of functioning systems, the organization's philosophy positively influences the culture of the organization.

On the basis of the results obtained it was stated that the culture of work safety in the 
so-called "turquoise" organization was the best rated. In the case of other production plants the culture of work safety in the organization having the most management systems implemented was best rated, and the worst in the plant having the fewest management systems.

\section{REFEENCES}

Aczer, A. D. (2012). Complete Business Statistics. Publisher: McGraw Hill Education, Inc.

Almklov, P. G., Antonsen, S., Bye, R., et al. (2018). Organizational culture and societal safety: Collaborating across boundaries. Safety Science, 110 (SI) Part: C, 89-99.

Blikle, A. J. (2017). Doktryna jakości. Rzecz o turkusowej samoorganizacji. Publisher: Onepres.

Brown, R. L., Holmes, H. (1986). The use of a factor-analytic procedure for assessing the validity of an employee safety climate model. Accident Analysis and Prevention, 18, pp. 445-470.

Clarke, S. (1999). Perceptions of organizational safety: implications for the development of safety culture. Journal of Organizational Behavior, 20, pp. 185-198.

Cooper, M. D., Collins, M., Bernard, R., et al. (2019). Criterion-related validity of the cultural web when assessing safety culture. Safety Science, 111, pp. 49-66

Cooper, M. D., Phillips, R. A. (1994). Validation of a safety climate measure. Paper presented at the BPS Occupational Psychology Conference, Birmingham, U.K.

Cox, S. J., Cheyne, A. J. T. (2010). Assessing safety culture in offshore environments. Safety Science, 34, pp. 111-129.

Dedobbeleer, N., Beland, F. (1991). A safety climate measure for construction sites. Journal of Safety Research, 22, pp. 97-103.

Ejdys, J. (Eds.) (2010). Ksztaltowanie kultury bezpieczeństwa i higieny pracy w organizacji, Publisher: Oficyna Wydawnicza Politechniki Białostockiej, Białystok.

Furman, J., Kuczyńska-Chałada, M., Poloczek, R. (2018) Improvement of production processes with the use of lean manufacturing tools, MAPE 2018, 1(1), pp. 529-535.

Gao, Y., Fan, Y., Wang, J., et al. (2019). The mediating role of safety management practices in process safety culture in the Chinese oil industry. Journal of Loss Prevention in the Process Industries, 57, pp. 223-230.

Glendon, A.I., Stanton, N. A. (2010). Perspective on safety culture. Safety Science, 34, pp. 193-214.

Goldenstein-Cole, K. (2017). An everyone culture: becoming a deliberately developmental organization. Harvard Educational Review, 87(1), pp. 150-154.

Goncalves, F., Anastacio, P., Waterson P. (2018). Maturity models and safety culture: A critical review. Safety Science, 105, pp. 192-211.

Guo, B.H.W., et al. (2016). Predicting safety behavior in the construction industry: Development and test of an integrative model. Safety Science, 84, pp. 1-11.

Hansen A. (1998), Bezpieczeństwo i higiena pracy, Publisher: WSiP, Warszawa.

Johnson S.E. (2007). The predictive validity of safety climate. Journal of Safety Research, 38, pp. 511-521.

Laloux, F. (2016). Reinventing Organizations: A Guide to Creating Organizations Inspired by the Next Stage of Human Consciousness. Nelson Parker.

Małysa, T., Nowacki, K., Furman, J. (2016). The risk management methodology in the metallurgical enterprise. 25th Anniversary International Conference on Metallurgy and Materials, Brno, Czech Republic, May 25th-27th, 2016. Conference proceedings, pp. 1925-1930.

Małysa, T., Nowacki, K., Lis, T. (2017). The correlation between structure of employment and accidents at work in metallurgical enterprises. 26th Anniversary International Conference on Metallurgy and Materials, Brno, Czech Republic, May 24th-26th, 2017. Conference proceedings, pp. 2244-2249.

Markey, R., Patmore, G. (2011). Employee participation in health and safety in the Australian steel industry, 1935-2006. British Journal of Industrial Relations, 49, pp. 144-167.

Mearns, K. et al. (2001). Human and organizational factors in offshore safety. Work Stress, 15 , pp. 144-160. 
Marans, R. W., Callewaert J. (2018). Evaluating Changes in Sustainability Culture: A Model for Universities and Other Organizations. International Journal of Law and Management, 60(5), pp. 1087-1096.

Naevestad, T.-O., et al. (2018). How can we improve safety culture in transport organizations? A review of interventions, effects and influencing factors. Transportation Research Part F-Traffic Psychology and Behaviour, 54, pp. 28-46.

Nielsen, K. J. (2014). Improving safety culture through the health and safety organization: A case study. Journal of Safety Reserarch, 48, pp. 7-17.

Nite, D.K. (2019). Negotiating the Mines: The Culture of Safety in the Indian Coalmines, 18951970. Studies in History, 35(1), pp. 88-118.

Nowacki, K. (2019). Modelowanie bezpieczeństwa w przemyśle. Gliwice: Wyd. Pol. SI.

Nunen, K. van, Reniers, G., Ponnet, K. (2018). Measuring and improving safety culture in organisations: an exploration of tools developed and used in Belgium. Journal of Risk Research, 21(5), pp. 622-644.

Nunnally, J. C. (1976). Psychometric Theory. New York: McGraw-Hill Book Company.

Oberg, J. (2018). Safety requires the right culture. Aerospace America, 56(10), pp. 36-41.

Odom-Forren, J. (2019). A Culture of Safety-Whose Responsibility? Journal of Perianesthesia Nursing, 34(2), pp. 223-225.

Schwartz, S., Adair, K., Bae, J., et al. (2019). Work-life balance behaviours cluster in work settings and relate to burnout and safety culture: a cross-sectional survey analysis. BMJ Quality \& Safety, 28(2), pp. 142-150.

Sorensen, J. N. (2002). Safety culture: a survey of the state-of-the-art. Reliability Engineering and Safety, 76, pp. 198-204.

Stemn, E., Bofinger, C., Cliff, D., et al. (2019). Examining the relationship between safety culture maturity and safety performance of the mining industry. Safety Science, 113, pp. 345-355.

Stichler, J. F. (2018). Creating a Culture of Inquiry in Your Organization. Herd-Health Environments Research \& Design Journal, 11(4) (SI), pp. 7-13.

Thorgren, S., Caiman, E. (2019). The Role of Psychological Safety in Implementing Agile Methods across Cultures. Research-Technology Management, 62 (2), pp. 31-39.

Yangho, K., Park, J., Park, M. (2016). Creating a Culture of Prevention in Occupational Safety and Health Practice, Safety and Health at Work, 7, pp. 89-96.

Abstract. Safety culture is one of the most important elements of the organization's culture. Its role is particularly important in production plants, where employees are more often exposed to threats related to the working environment. The safety culture is strongly associated with the organizational level of the enterprise, which is largely influenced by the implemented management systems. The article presents the results of the evaluation of work safety culture in production plants with different functioning management systems, including the so-called turquoise organization. A relationship between the organizational level of the plant and the culture of occupational safety was stated.

Keywords: safety culture, management systems, turquoise organization 